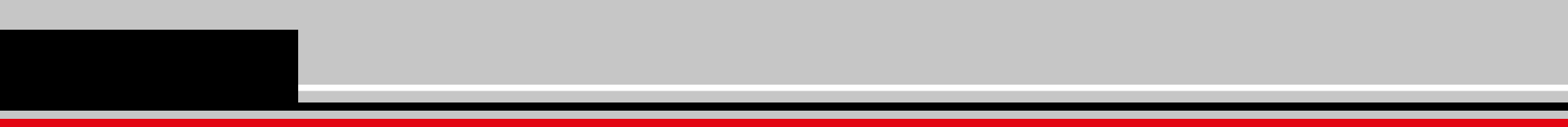




\section{Diseño tipográfico para libros: Una tarea de mectición del tiempo}

Castro, M. (2013). Diseño tipográfico para libros: Una tarea de medición del tiempo. Designia, 2(1), 86-110

\section{Typographic design for books: $A$ task time measuring}

\section{Resumen:}

\section{Palabras clave:}

Diseño Gráfico, Diseño editorial, tipografía, letra, libros, composición

\section{Key words:}

Graphic design, Editorial Design, typography, letter, books, composition..

Recibido: 19-abr-20 12

Aceptado:3-oct-2013

\footnotetext{
* Diseñadora Gráfica Universidad Nacional de Colombia. Profesora auxiliar e investigadora del grupo XISQUA de la Universidad de Boyacá.

email: anacastro@uniboyaca.edu.co
}

El presente artículo de reflexión tiene por objetivo abordar el diseño de la pásina y por extensión del libro, a partir de experiencias de aula y profesionales, como un ejercicio integral que enriquece la diagramación al proponer un tratamiento tipográfico para la producción editorial, proceso que busca comunicar más que informar. El trabajo resume los resultados de la investigación desarrollada con el grupo de investigación Xisqua, titulada "Tiempo, Silencio y Espacio, Herramientas para la construcción de libros". Como factor de enlace entre el diseñador, la pieza diseñada y el lector se toma el concepto del tiempo, en aras de comprender ampliamente las posibilidades de uso de la letra.

Se ejemplifican cada una de las condiciones posibles de la relación entre los mencionados elementos y se analizan las connotaciones de cada situación. Además, se ofrece al diseño tipográfico una fundamentación teórica que permite proyectar al diseño editorial más allá de lo determinado por la moda o los usos habituales. Como resultado de esta reflexión, el diseñador gráfico tiene acceso a un repertorio de recursos que aplicados al diseño, pueden potenciar las condiciones visuales de los textos diseñados para libros. Asimismo, desde lo teórico se aporta a la construcción de la semiosis del diseño editorial, mediante sentidos y significados surgidos del manejo formal de la palabra.

\section{Abstract}

This article of reflection is based on teaching and professional experiences. It aims to address page-design and by extension bookdesign. This is as a comprehensive exercise where the layout is enhanced by proposing a typographic treatment for the publishing process, which intends to communicate more than to inform. This paper summarizes the results of research undertaken with the research group Xisqua, entitled "Time, Silence and Space, Tools for building books." As a linkfactor between the designer, the designed piece and the reader, it has been considered the concept of time in order to fully understand the possibilities when using the letter. Each single possible condition regarding the relationship between the above elements is exemplified while the connotations of each specific situation are analysed. Furthermore, the typographic design is provided with a theoretical foundation that allows projectins the editorial design beyond what is determined by fashion or conventional uses. $A_{s}$ a result of this reflection, graphic designers are given access to a wide range of resources which if applied to the design may foster the visual conditions of the texts designed for books. Likewise the editorial design semiosis build-up is enriched from a theoretical view, by means of a sort of feelings and meanings emerged from the formal usage of the word. 
Crear un lenguaje gráfico es un proceso que se alimenta de la experiencia. Este ejercicio comienza con la conceptualización del proyecto y se adentra en el campo del Diseño Gráfico en procura de materializar las ideas de la forma más eficiente. Apoyado en lo visual, el diseño propone soluciones no verbales que posibilitan la decodificación del mensaje. El diseño, entonces, trasciende el plano formal, estructura al mensaje, posibilita la comunicación, construye redes.

Los recursos visuales empleados en los distintos hechos gráficos, aun siendo los mismos, han de tener un tono distinto en función de la pieza trabajada. Al diseñar las pásinas de un libro, se proponen los elementos formales que generarán o no la conexión del lector con eventos, personajes o enunciados, en un primer paso en la construcción de la cadena de la cultura. Al diseñar un libro se debe

Hacer que nazca de manera bella; constituirlo en un todo coherente que conjugue con armonía: tipografía, composición, color y papel, y que nos sumerja visualmente en el tema relatado. Un objeto perfecto, cuyo estilo establezca en él vida propia y nos seduzca. Un objeto para tomar entre las manos y ser recorrido con los ojos (Granados, 1992).

De tal forma, se requiere un proceso que confiera a los elementos tal trascendencia, hilvanando con sutileza lo técnicamente correcto. El tiempo, determinante de nuestra existencia, encuentra un espacio en la mesa de trabajo de quien diseña, en procura no solo de componer sino de construir ese instante en que la sucesión lógica de los hechos se interrumpe para dar espacio al universo creado por quien lee. Diseñar páginas para libros es una tarea de medición del tiempo. Del tiempo en secuencia, del tiempo real, del tiempo en la historia. 
A continuación, se exponen las diferentes relaciones que se entablan entre los involucrados en el proceso de la transmisión cultural al cual nos referimos, en concordancia con la intención de crear momentos pertinentes para cada quien, al emplear como soporte de tales relaciones la palabra escrita, y por extensión, al libro como ejercicio fundamental del diseñador gráfico.

\section{En el primer mapa (figura 1)} se estructuran las posibilidades que más adelante se exponen y amplían, las cuales comprueban las relaciones entre los distintos actores del proyecto editorial con el tiempo, factor determinante en el acto de diseñar piezas cuya base es la tipografía. La propuesta de construcción editorial que finalmente se argumenta está sustentada en una solución técnica al tratamiento tipográfico, en procura de dominar los tiempos en la lectura. A su vez, está basada en la experiencia profesional, el desempeño académico, y ante todo, la experiencia visual. No pretende desvirtuar otras fuentes, sino por el contrario, funcionar como un apoyo para quien trabaja en el diseño, en la producción de libros y medios impresos, pues brinda un soporte teórico a las respuestas que se aportan de manera cotidiana al problema de la composición tipográfica.

En tanto se avanza en la exposición, el mapa inicial se amplía en diferentes direcciones con el fin de explicar con mayor precisión cada uno de los elementos relacionados. Los mapas están acompañados por un pequeño sistema de convenciones que ayuda a su interpretación, sin ser una clave exacta. Así, en el texto se enlazan las propias experiencias visuales con cada punto enunciado. 
CON EL LIBRO

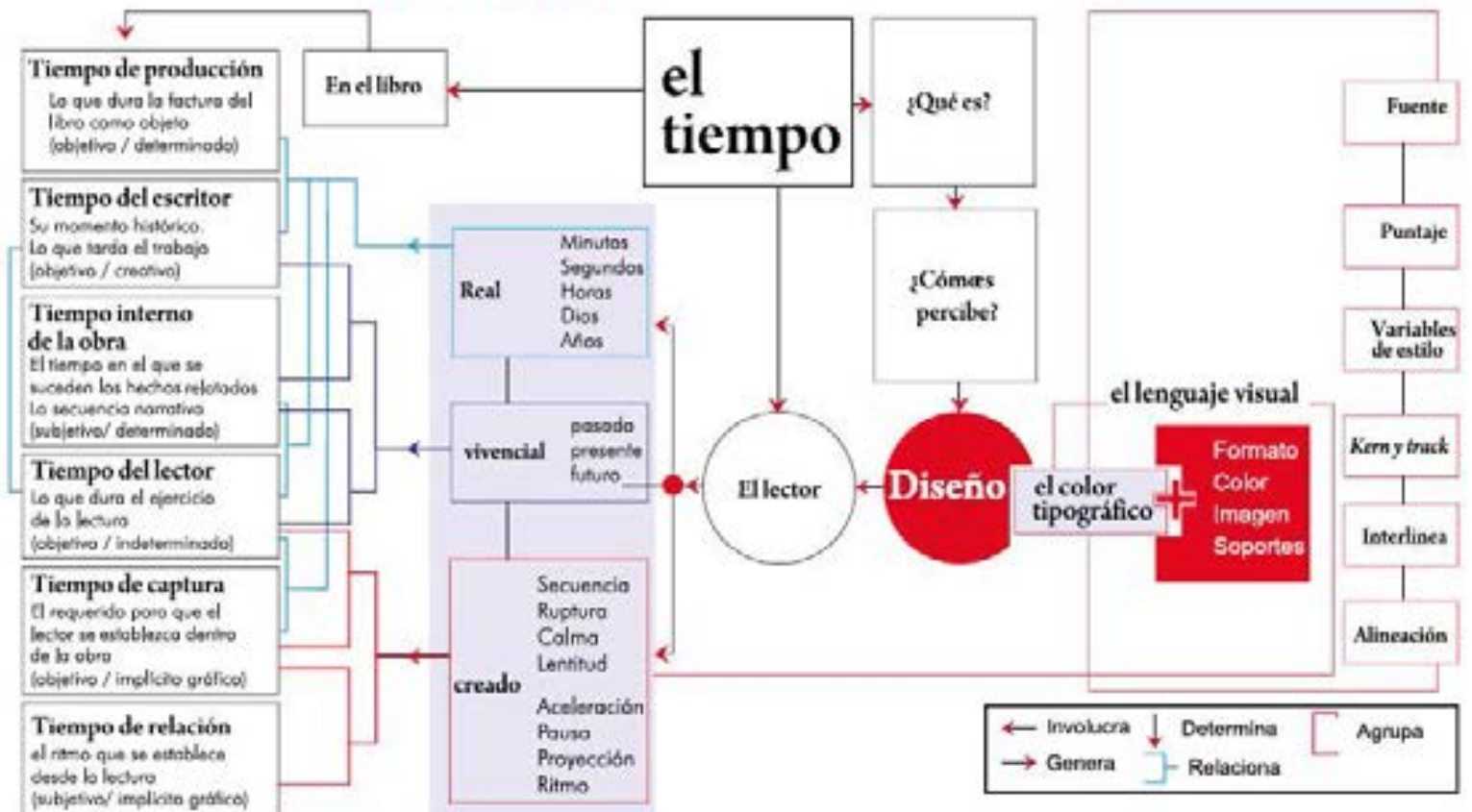

Figura 1. Diferentes maneras de percibir el tiempo en relación con el hibro Fuente: Autora

\author{
"La Cultura Maya nos ha legado un \\ calendario que se basó en la observación \\ de las lases de la luna. En él se cuentan \\ 28 dias por cada luna ( 4 fases de 7 \\ dias), lo que da como resultado 13 lunas \\ por año o 364 dias, más un dia luera del \\ tiempo llamado "dia verde", cones- \\ pondiente a un salto en el movimiento \\ helicoidal de los sistemes gallicticos.
}

\section{LA PERCEPCIÓN DEL TIEMPO}

El tiempo, de acuerdo con esta propuesta, exige un tratamiento cuidadoso. No basta el reconocimiento juicioso de la estructura de construcción de la página: diseñar libros equivale a manejar el tiempo en virtud de múltiples elementos.

Objetivamente hablando, el tiempo es la magnitud física que permite la medición en la sucesión de un antes y un después. Las condiciones variables entre esos dos momentos y que son percibidas, determinan la existencia del pasado, del presente y del futuro. La percepción que tenemos del tiempo lo convierte en algo personal, determina los ritmos y concreta las posibilidades de su apropiación. Constantemente, y en una moderna manera de considerarlo como elemento de inmenso valor, nos "proyectamos" en el tiempo, buscamos maneras de "ahorrarlo", sufrimos porque se "agotó". De igual forma, culturas milenarias como la Maya", Creian que si eran 
capaces de medirlo con exactitud, también podrían predecir el momento en que iban a suceder ciertos eventos en el futuro, como guerras, victorias, desastres y todas las acciones y sucesos que ya habian sucedido en el pasado; esto muestra que para los Mayas el tiempo era cíclico, por lo que contando con un calendario perfecto podrian llegar a predecir el futuro, convirtiéndose así, en los Señores del Tiempo (Lóper, 2008).

\section{Resulta interesante pensar el concepto} del tiempo como uno de los recursos para la construcción de un libro. Los tiempos empleados en la preproducción - la producción son quizás los de mayor relevancia en términos económicos, pero los menos importantes en la elaboración de un lenguaje visual propio para el producto final. El lenguaje visual, como "base de la creación del diseño" (Wong, 1980, p. 9) responde a problemas de comunicación especificos y se alimenta de una amplia comprensión de "principios, reglas o conceptos, en lo que refiere a la organización visual" (Wong, p. 9).
Como el mismo autor propone, "una solución inspirada podrá ser conseguida de forma intuitiva, pero en casi todos los casos el diseñador deberá confiar en su mente inquisitiva, la que explora todas las situaciones visuales posibles, dentro de las exigencias de los problemas especificos" (p.9)

\section{GENERALIDADES}

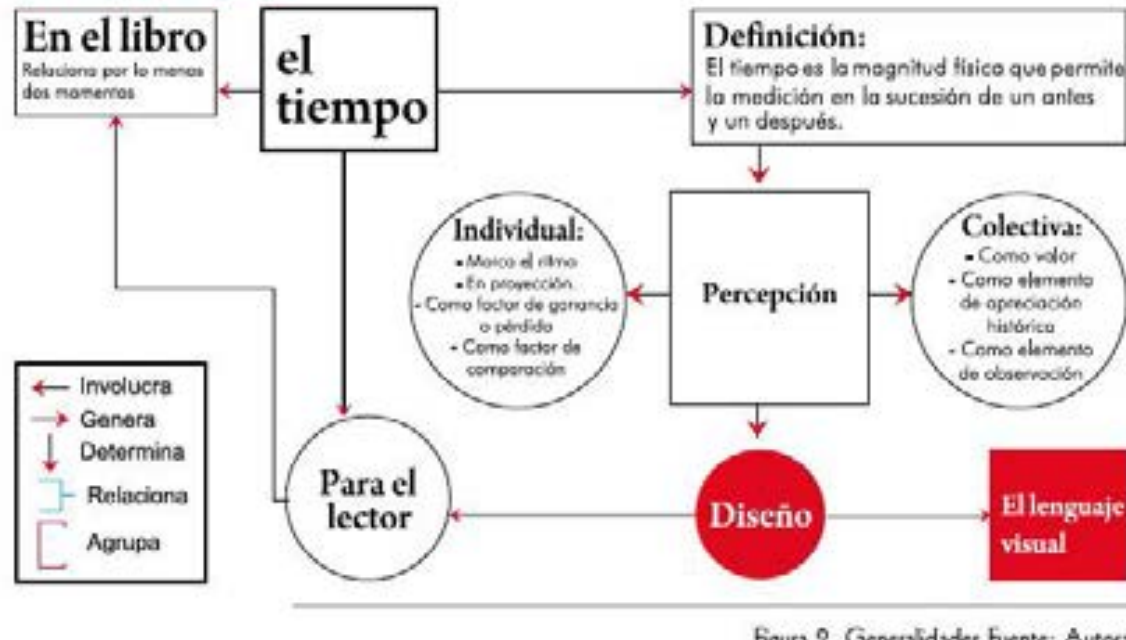

El tiempo que empleará el lector en recorrer la obra, condición en apariencia independiente del diseño, es un elemento que en alguna medida también compromete el trabajo del diseñador. Si se cuenta con un buen lector, el tiempo incluirá lo necesario para completar el círculo de la comunicación, sin prisa. Es posible que esta actividad esté integrada al quehacer cotidiano. Esta es una seducido o modelizado, utilizar el término empleado por Giorgio Antei al expresar la relación del texto con la cultura cuando menciona

El derechio de un texto de figurar en la biblioteca de la cultura, lejos de set automático, depende de su índole creativa o, más exactamente de su carácter modelizante. A su vez, este presupone, junto a la no inmediatez de los signos, la capacidad de "tramitar" memoria (sobre la base del pastulado que la cultura es la biblioteca de la memoria) (Antei, 1992, p. 24). 
Para tales efectos se tiene sólo un instante: el lector se atrapa en las primeras diez páginas o se pierde para siempre. Ese minuto, de vital importancia, compromete el trabajo del diseñador, sin lugar a dudas.

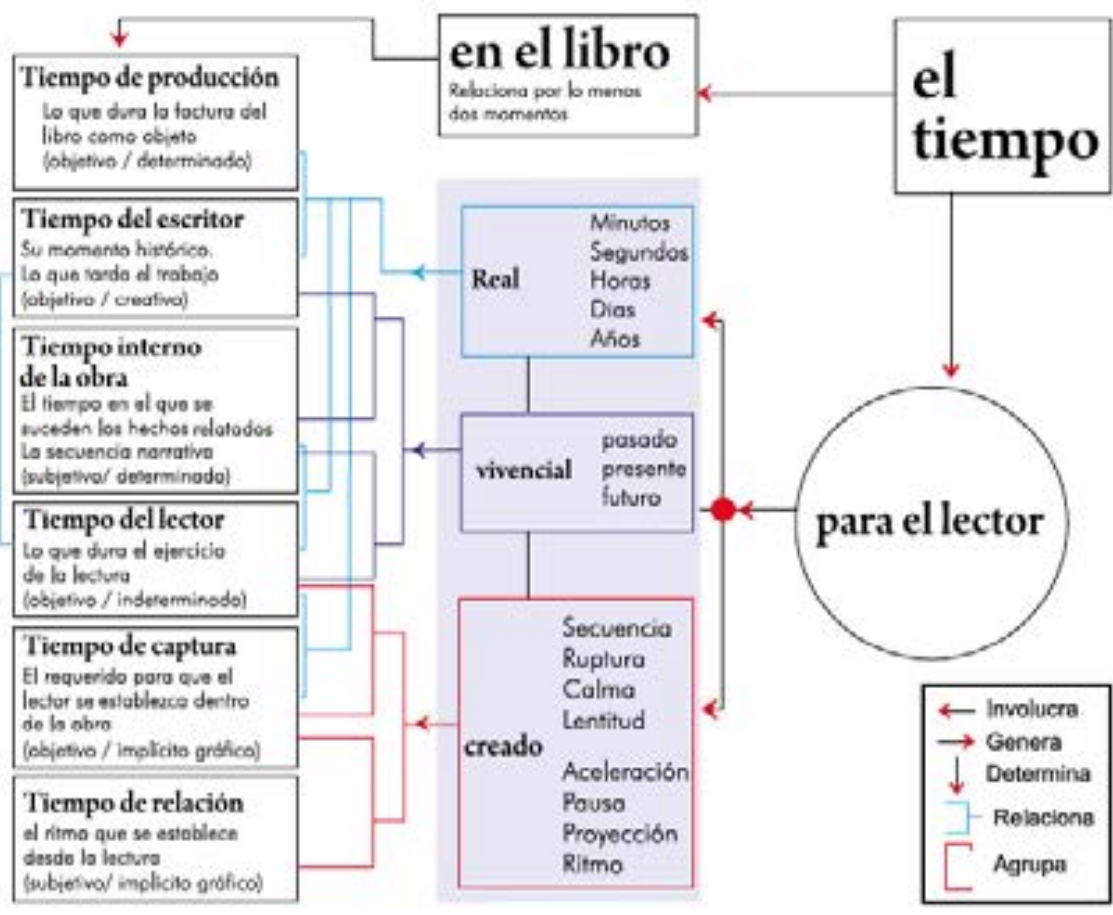

Firges 3.El ticmpo con relación al lextor Fisente: Austora

\section{EL TIEMPO REAL, EL TIEMPO VIVENCIAL Y EL TIEMPO CREADO}

Indistintamente, el nuestro es un tiempo en constante aceleración. Batallamos la lucha contra la inmediatez. Según señala Satué, el libro es por definición "una de las mayores correas de transmisión de la cultura occidental" (1990, p. 31), establecida entre dos momentos -como mínimo- absolutamente reales, si tan solo nos referimos a la posibilidad física de entablar un diálogo entre el escritor en ejercicio y la realización de la lectura. El libro suele ser una referencia a eventos históricos que poseen su propio reloj, pues más alla del tiempo en que se conjuguen los hechos, se citan presentes ya idos. Por supuesto, es válido contar con los tiempos internos en la obra: válidos en ese universo onírico en que se sumerge quien lee, válidos en su proceso de internalización de las situaciones creadas, cuando por momentos se asume el rol de los personajes y gracias a la habilidad de quien escribe, se posibilita la apertura de portales en el tiempo, creados en la sicología del lector.

De tal suerte, el diseñador se involucra en este juego al escoger los elementos que permiten crear esa nueva dimensión y al incluir desde su manejo todo lo necesario para generar el tiempo suficiente, aquel que lleva al lector a establecerse en el objeto de la lectura. El color de las púginas invitará al lector a adentrarse en el interior de la historia, lo interesard. Entonces, es cuando el tiempo hace su primera y estratégica entrada en el repertorio de elementos que, conjugados, definen un buen libro desde la mirada del diseño.

\section{En Diseño Gráfico, la preocupación} por una selección correcta de los elementos tipográficos es un tema recurrente en los espacios de reflexión sobre la profesión. Un ejemplo de esta recurrencia es abordada por diferentes autores en el sitio web Foroalfa. Todos 
ellos coinciden en las posibilidades expresivas del texto como base de la comunicación escrita, teniendo en cuenta esta doble dimensión, la der ser palabra y a la vez forma. Silverio Contreras apoya aquella condición en que la letra se convierte en un elemento valioso al completar la historia contada:

Lo que quiero destacar es el aspecto discursivo del carácter, de la forma de la letra, y su capacidad de influir en la reacción que se produce entre el texto y el lector. Lo que lleva al tipo de letra a ser el conducto idóneo del mensaje, intención, idea o hasta sentimiento (Contreras, 2012).

De otro lado, también en Foroalla el colombiano César Puertas (2012) propone, desde el diseño de la letra misma, un mayor acercamiento al aspecto sensible de las formas como recurso fundamental en la consecución de índices de lecturabilidad más altos: "dichas estrategias aplicadas al diseño de tipografía, sin tener en cuenta el principio orgánico de modularidad no geométrica de los trazos, siempre dejan como resultado letras excesivamente rigidas, con un repertorio de formas y aplicaciones bastante limitado". (Puertas, parr. 19)

Al integrar a ese primer interés el concepto de percepción (entendido como un grado más alla de la simple sensación), construido a partir del significado que atribuimos a la información recibida por medio de nuestros sentidos o sensaciones, significado que supone la integración del mundo real (la realidad objetiva) y los estímulos obtenidos a través de los sentidos, que al acumularse en la memoria generan la experiencia como resultado de la organización de esa información, se desarrollan los esquemas de selección de determinadas sensaciones y la eliminación de otras, de acuerdo con el concepto que oriente el diseño.

Dicho proceso de selección y eliminación de los elementos visuales ha sido históricamente preccupación del diseñador. Esta condición -congruente con las épocasresponde a las tendencias de la sociedad $e$ indudablemente a las intenciones comunicativas del propio diseñador, quien de acuerdo con diversos factores realiza inicialmente la selección de los elementos tipográficos para el caso particular que nos ocupa: el diseño de la página del libro. Satué menciona al respecto: "[... ] la letra, lejos de su condición teóricamente neutra, representa la cultura temporal y concreta de su tiempo, y en función de ello es susceptible de ser sacralizada o prohibida, defendida o atacada [...]" (1990, p. 184).

De tal manera, la construcción de significados al diseñar con elementos tipográficos equivale a trabajar de forma equilibrada con elementos que definen las tensiones o dilaciones del tiempo, según se requiera. Estos se exponen a continuación. 


\section{EL CONTROL DEL TIEMPO EN LA PÁGINA DISEÑADA}

Elementos del diseño que permiten establecer relaciones entre el autor, lo lé́do y

el lector con respecto al tiempo
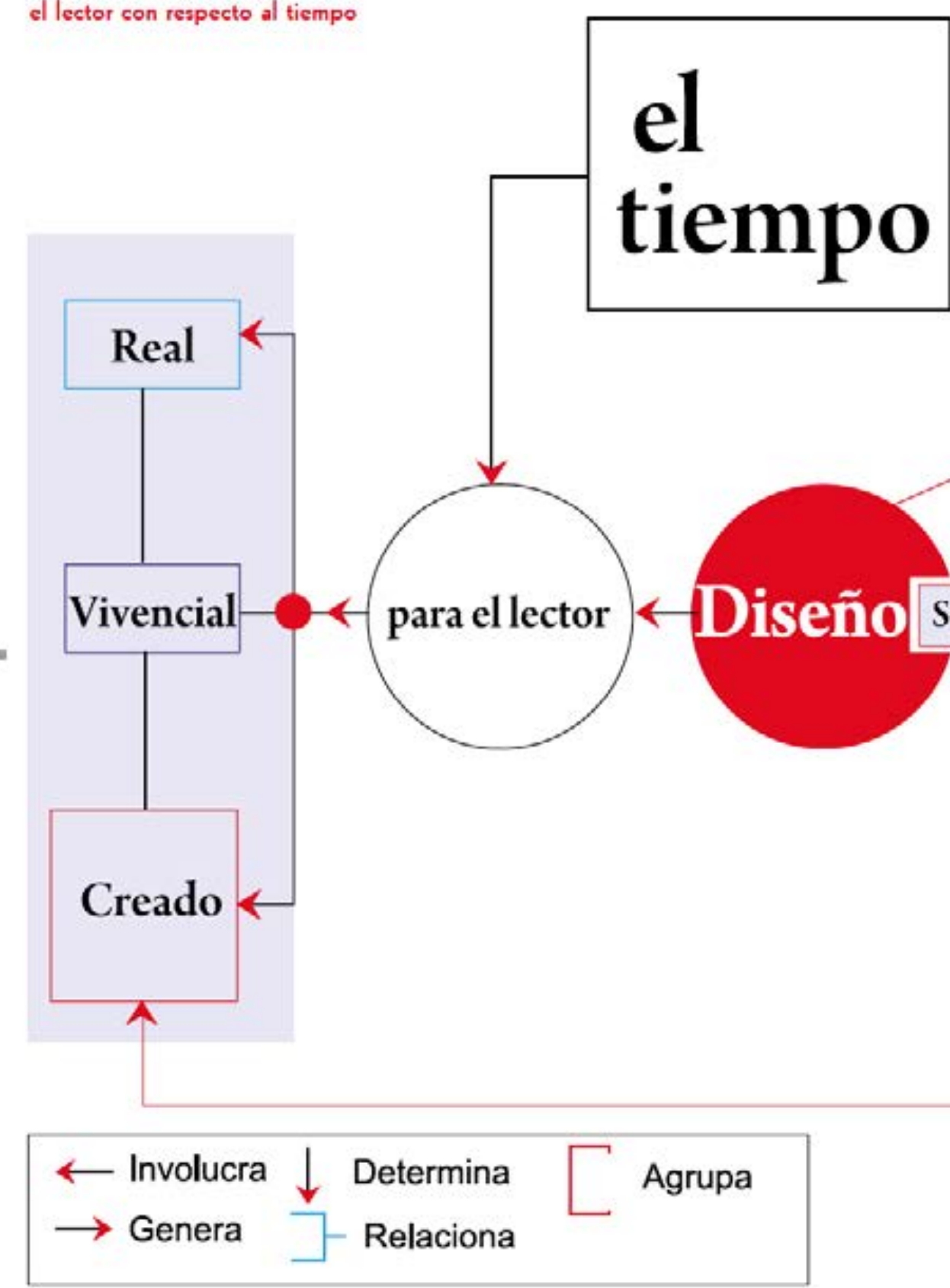

El lenguaje visual

Formato Color 


\begin{tabular}{|c|c|c|c|c|c|}
\hline & Romanas & $\begin{array}{l}\text { Modernas } \\
\text { Clásicas }\end{array}$ & Secuencia & Ritmo & Calma \\
\hline \multirow{3}{*}{ Fuente } & $\begin{array}{l}\text { Egipcias } \\
\text { De Palo Seco }\end{array}$ & & Aceleración & & \\
\hline & Goticas & & & & \\
\hline & Ornamentales & & Ritmo & Secuencia & Lentitud \\
\hline \multirow{2}{*}{ Puntaje } & Para cuerpo & $-7 / 10 \mathrm{pt}$ & Secuencia & Calma & \\
\hline & de texto & $11 / 14 \mathrm{pt}$ & Aceleración & Ruptura & \\
\hline & Itálica o cursiva & & Proyección & Ritmo & Secuencia \\
\hline \multirow{4}{*}{ Variables de estilo } & Extendida & & Proyección & Calma & Lentitud \\
\hline & Comprimida & & Aceleración & & \\
\hline & Negrita & & Ruptura & & \\
\hline & Ligth & & Ritmo & Calma & \\
\hline \multirow{3}{*}{ Kerny track } & Amplio & & Secuencia & Calma & Ruptura \\
\hline & Normal & & Ritmo & & \\
\hline & Ajustado & & Aceleración & & \\
\hline \multirow{3}{*}{ Interlinea } & Amplia & & Lentitud & Calma & \\
\hline & Normal & & Secuencia & Ritmo & \\
\hline & Ajustado & & Aceleración & Ruptura & \\
\hline & Izquierda & & Secuencia & Ritmo & Pausa \\
\hline \multirow{3}{*}{ Alineación } & Derecha & & Lentitud & Ruptura & \\
\hline & Central & & Ruptura & Ritmo & \\
\hline & Forzada & & Ruptura & & \\
\hline & Irregular & & Ritmo & Secuencia & Calma \\
\hline
\end{tabular}




\section{EL SET O COLOR}

\section{ITIPOGRÁFICO}

Este término reúne las condiciones que desde la dimensión física de la letra, hacen que un texto se convierta en algo aprehensible por el lector, con mejores condiciones de lectura. La definición técnica de esta denominación, aplicada a las artes gráficas, hace referencia al control ejercido en virtud del espaciado de las letras y las palabras. Estas condiciones, conocidas como track y kern, a partir de la implementación de las tecnologías de la informática al Diseño Gráfico, deben ser observadas de manera inde. pendiente del proceso tecnológico, ya que el cálculo digital del blanco entre caracteres se hace de manera exacta y no cuenta con la necesaria apreciación visual. El tratamiento tipográfico regido por el ojo entrenado en establecer la diferencia en el correcto manejo de dichas condiciones, permite una percepción clara de lo escrito.

La legibilidad, condición primaria definida por el conocimiento del idioma y el entrenamiento básico en la asociación de caracteres reconocidos, se diferencia de la lecturabilidad, condición totalmente deseable en un texto, al estar determinada por el control del diseño. También son importantes los factores culturales, tal y como se deduce de lo citado por Satué, quien retoma las observaciones de Paul Renner, resumidas en su libro Die Kunst der Typographie, cuando anota: "por ejemplo, la necesidad de enfatizar el ritmo natural de la lectura occidental, de izquierda a derecha, para facilitar y optimizar con ello la legibilidad del nuevo diseño" (Satué, 1990, p. 177). Por ende, la habilidad del diseñador en manejar la 'colorización' de su texto es equivalente al nivel de eficiencia en la lectura de su trabajo, a partir de la medición de los ritmos o tiempos internos de la pieza en creación.

Igualmente, tal habilidad se complementa con un trabajo plenamente geométrico, según lo estudiado por Gaitto (2008): "Existe, sin embargo, una ley para la armonia de blancos entre signos. Dicha ley es una aproximación a como se deben resolver los blancos, está basada en relaciones matemáticas, peto el trabajo debe realizarse desde lo óptico especificamente." (p. 7)

Luego de las consideraciones hechas para comenzar con una selección tipográfica coherente, surgen las posibilidades de acercarse a la mancha de texto como elemento para diseñar. La acepción cromática de este término se define como la interferencia que generan los elementos gráficos y tipográficos contemplados en un diseño, conjuntamente con su peso respecto al blanco de la página. El manejo de la mancha tipográfica o el control del set, incluye:

1. El control del kerning y el tracking.

El interletrado para los cuerpos corrientes de lectura (cuerpo 12 o menos) está determinado en su mayor parte mecánicamente por los programas de ajuste establecidos por los fabricantes de los equipos o por el tipógrafo. Si en un 
programa de fuentes el ajuste resulta insuficiente, las variaciones que surjan en el espaciado perjudicarán la percepción del color tipogrático. A veces hay huecos desagradables que ocurren entre y alrededor de combinaciones particulares de letras. Las combinaciones conflictivas entre signos surgen al vincular contraformas que generen mayor - menor aire de lo establecido (Gaitto, 2008, p.8).
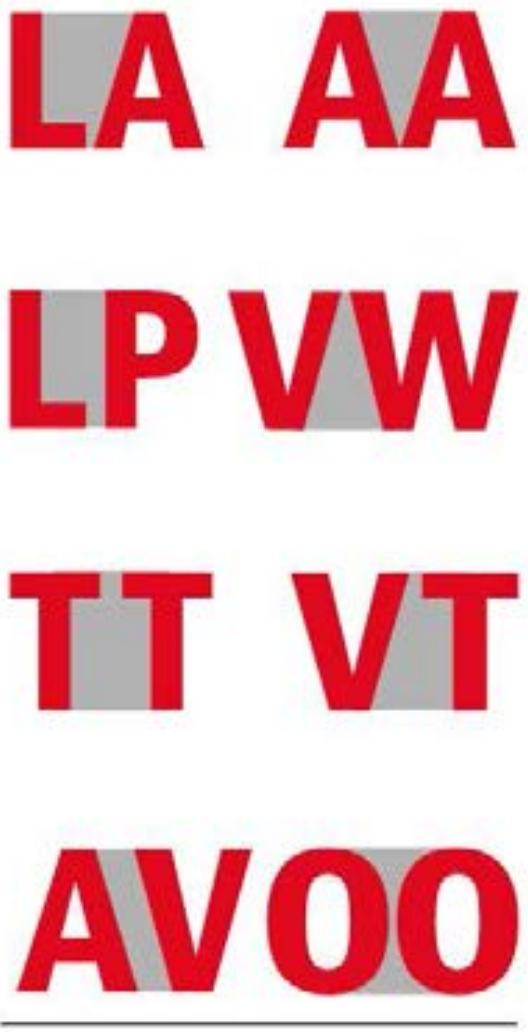

Figua 5. Contraformas Fuente: Gitto. 2008

\section{La fuente.}

Se entiende por fuentes las influencias genéricas que inspiran una forma de letra; su clasificación surgió como consecuencia del análisis de los antecedentes de las categorias existentes. Comprenden: decorativa/pictónica, caligráfica, romana, vernácula del siglo XIX y una categoría adicional que resume influencias formales más recientes (Baines, 2005, p. 52).

Seleccionar una fuente tipográfica debe ser un ejercicio de plena conciencia de las condiciones anatómicas del tipo. Téricamente, un tipo de rasgos romanos ha de contener lo deseable para el manejo de textos en piezas editoriales. Las fuentes de palo seco o grotescas se deben usar con el cuidado apropiado. Son tipos hermosos, balanceados y de buena estructura, pero generalmente no funcionan bien en cuerpos de texto largos, apreciación que confirma Satué al comparar los libros compuestos en tipos de palo seco y los editados en tipos romanos:

Más alla del contexto vanguardista y experimental en que se produjo la revolución tipográfica de los años veinte, los tipos de palo seco no han conseguido desbancar - la tipografía romana clásica de los libros de texto general y a los de ficción, literatura o poesía en particular (1990, p. 184).

En estos términos, y en concordancia con lo expresado por Gaitto, seguramente resultan más favorables aquellos de condensación ligth sin compresión y con un espaciado suelto. Los tipos de palo seco, que se manejan en negrita, bold o comprimidos, ganan peso, ennegrecen la mancha y dificultan la lectura de cuerpos de texto largos.

Las tipografias romanas clásicas, con sus serifs de curvas suaves y pesos de trazos finos y gruesos, funcionan bien cuando se las compone apretadas pero sin que se toquen, excepto en aquellos casos donde los serif están unidos por ajustes de espaciado. Las combinaciones que se tocan no deberian incluir dos letras de trazo vertical, ya que al acercar los trazos verticales pueden aparecer falsas contraformas que dificulten la legibilidad. (Gaitto, 2008, p.9). 
La selección de una fuente de carácter romano implica un tiempo de solemnidad, hace parte de una historia, permite un amplisimo momento de contemplación. El carácter romano habla de una época y evidencia el pasado. Su lectura se hace pausada y por supuesto sencilla. Define el cuerpo de texto asi trabajado, un tono de grato gris medio cálido, amable y ligero, pero con la contundencia de su innegable presencia. Sus espacios generan "cunas" agradablemente redondeadas donde el ojo cierra visualmente los espacios para no perder el hilo. En medio de la calma sugerida de los textos romanos, la ligereza de su lectura alimenta la rapidez del contacto con este tipo de cuerpos de texto.

De igual manera, un cuerpo de texto 97 desarrollado con caracteres "de palo seco" habla de la modernidad, de lo transparente a lo completamente negro en proporción con su condensación. Diseñar textos con caracteres de esta naturaleza es un acto de osadía y de confianza en el lector objetivo. Su claridad y sencillez apoyan una lectura fácil, quizás no constante. Evadidas de lo superfluo, las "grotescas", permi- ten al lector una visualización amplia, distante. Su tiempo es el del presente. Con relación a lo mencionado por Gaitto (2008), los espacios entre unas y otras deben cuidarse pues es sencillo perderlos o generar tales amplitudes que la ruptura en la línea del texto es inevitable (Figura 7):

Si tomamos como base el ancho del bastón de una letra, los signos regulares se deben espaciat entre sí en esa medida base, los circulares y triangulares se espacian entre sí un cuarto de la medida base, y ambos con los regulares se distancian en la mitad de la medida base (p. 2).
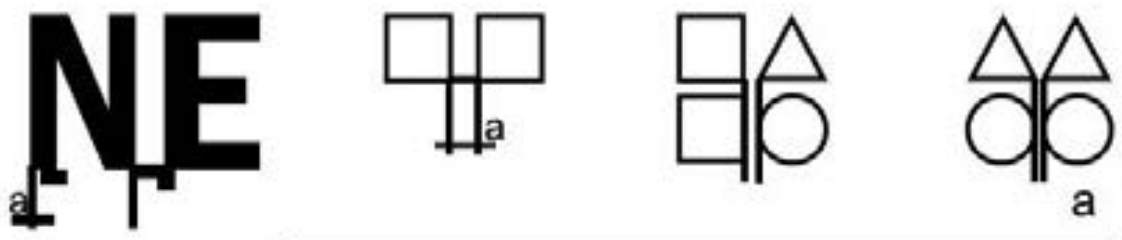

a

Figura 6. Espaciado de tipos de palo seco Fuente: Gaitto, 2008

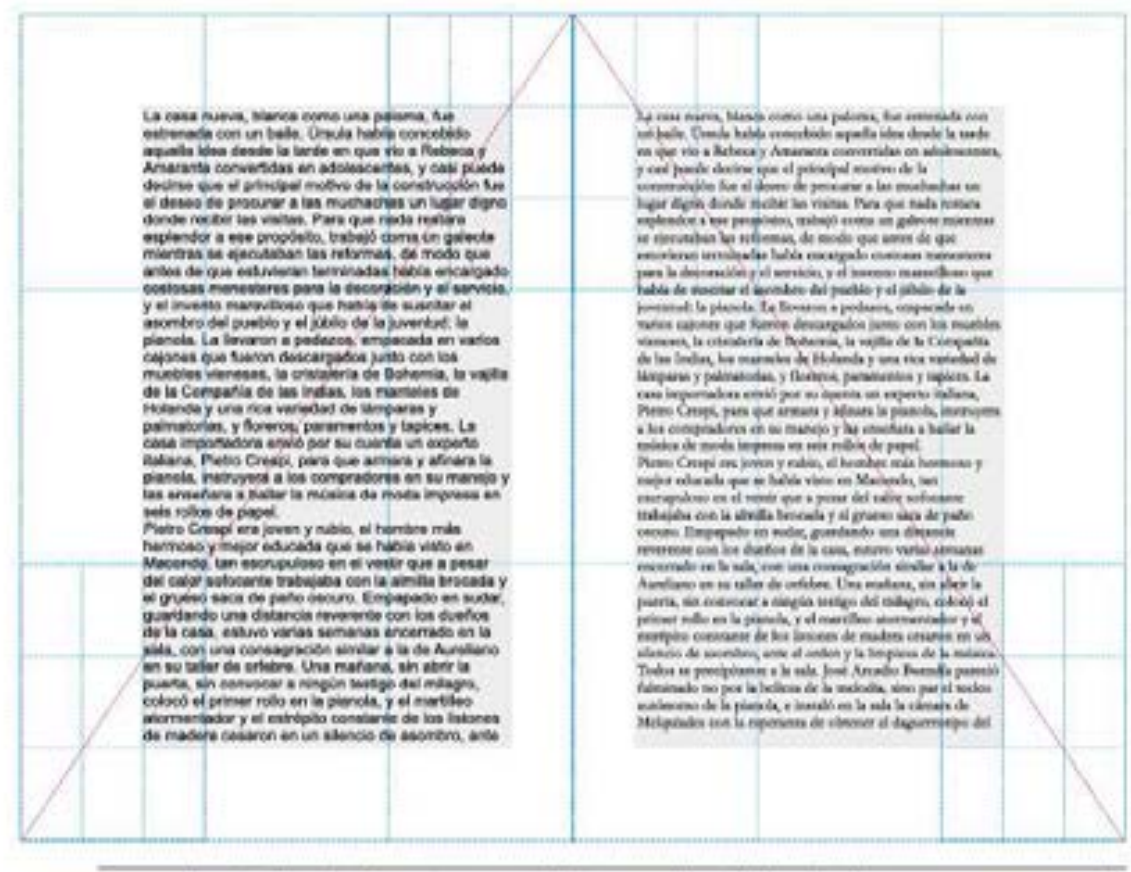

Figura 7. Ejemplo de un mismo tecto de (ien años de soledad, trabujado en caracteres romunos y de palo seco (compuesto en formato rectangular fureo, igual puntaje y fuemtes Avial y Garamond).

Fuente: Autora 


\section{El contraste y su transición}

entre las astas.

El contraste es definido como

la "característica que describe la diferencia relativa entre el grosor y el perfil de una letra" (Baines, 2005, p. 55). Las letras pueden clasificarse de acuerdo con distintos tipos de contraste: ninguno, medio, alto y exagerado. Por su parte, la trancisión "describe como se relacionan el grosor y el perfil de una letra" (Baines, 2005, p. 55). Según el mismo autor, esta caracteristica cuenta con cuatro variaciones: ninguna, gradual, abrupta e instantánea. Para Gaitto, resulta importante verificar la incidencia de la trancisión en el interletraje:

Las tipografías con contraformas estrechas y troncos más pesados requieren un menor espaciado alrededor. Las normas para el espaciado de tipografías itálicas son esencialmente las mismas que se aplican para las letras romanas. La estructura de los trazos que ascienden y descienden en algunos estilos itálicos puede, $\sin$ embargo, establecer una distancia óptima de interletrado. Este también es el caso de las tipografías derivadas de la escritura manuscrita donde las ligaduras de unión determinan el nitmo del espaciado (Gaitto, 2008, p. 4).

Es recomendable seleccionar de preferencia tipos cuyas astas no tengan un contraste demasiado amplio. Este elemento acompaña la lectura y la facilita. Además, los tipos con tal atributo son hermosos, generan cadenas.

\section{Vanos amplios.}

Es otro atributo deseable en un buen tipo para composición editorial. Los espacios amplios aclaran el set, dada la necesidad de ampliar el interletraje para compensar el blanco.

\section{Serifas.}

Los tipos serifados tienen mejores condiciones de lectura en la medida que los caracteres se enlazan los unos a los otros visualmente. Evitar los tipos de serifas cuadradas o de mucho peso en textos demasiado largos es una buena opción.

\section{La interlínea.}

Este factor, condicionado por valores predeterminados en los programas de edición de texto, es un elemento de gran importancia en la construcción de textos para libros. No debe dejarse simplemente sometido al cálculo matemático: es importante comprobar como interactúan los demás componentes con la interlínea propuesta y balancear el nivel de densidad de la mancha con el espaciado de la línea.

En la medición de los tiempos que debe considerar el diseñador al momento de crear el espacio requerido por el lector, la interlínea funciona como la pausa necesaria en la armada de un texto fácilmente legible. La claridad del texto se apoya en una interlinea suficientemente amplia que no llegue a fracturar la lectura. El juego del color para la mancha tipográfica abre un espectro interesante desde la posibilidad de explorar esta condición, generar gradaciones, transparencias y fusiones. En definitiva, jugar al diseño solo con la línea de texto enriquece la página y marca el tiempo de la lectura (figura 8). 

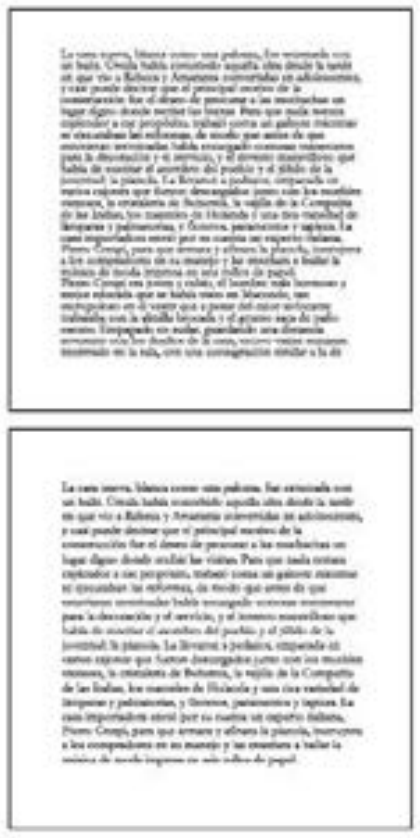

Lom

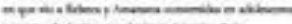

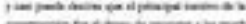

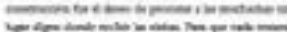

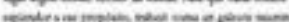

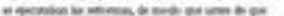

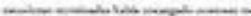

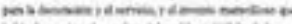
intion -

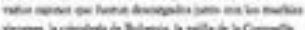

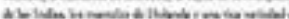

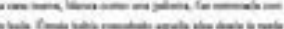

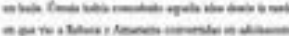

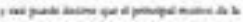

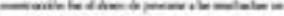

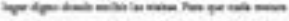

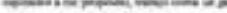

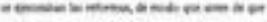

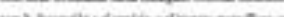

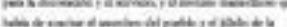
-

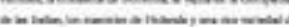

Figura 8. Ejemplo de totos de Gien Allos de Soledad, compucstos on Garamond, al miamo puntaje, con interliness (de arribu bajo y de équierda a derecha) al 100,130. 150 y 200 de la altura del carácter. Fuente: Autcea

\section{La alineación.}

Aparentemente, la línea se ajusta a la derecha, a la izquierda, al centro, se justifica o se fuerza a ambos lados sin mayores pretensiones. Sin embargo, la alineación correcta evita errores comunes como las calaveras (blancos inconstantes que se presentan en una línea de texto y se perciben como pequeños huecos en la mancha tipogrática), los rios (alineación vertical de varios de esos huecos en líneas consecutivas), o los huéffanos (lineas de texto, compuestas de una palabra o menos, que concluyen un párrafo o una columna).

Determinar cómo alinear no es un simple requisito estructural, pues depende además del ancho de la columna y de otras condiciones aceptadas. Un texto de extensión considerable funciona mejor alineado a la izquierda, mientras que una columna de un periódico se espera verla ajustada a ambos costados. En cualquier caso, la determinación depende del contexto y de la pieza en que ha de implementarse el texto. Las posibilidades expresivas del mismo están limitadas por su contenido. Así, un texto es más expresivo y tiene mejor condición de lectura si se encuentra alineado a la izquierda, una alineación a la derecha sólo soporta eficientemente textos de moderada extensión, y las alineaciones centrales son de uso muy restringido (higura 9). 


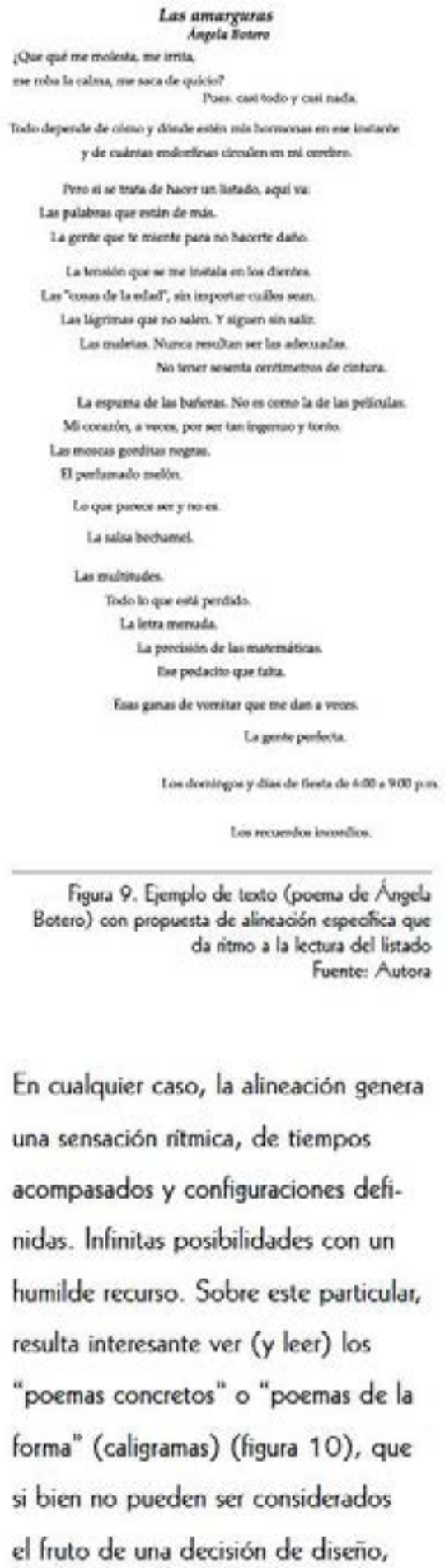

En cualquier caso, la alineación genera una sensación ritmica, de tiempos acompasados y configuraciones definidas. Infinitas posibilidades con un humilde recurso. Sobre este particular, resulta interesante ver ( $y$ leer) los "poemas concretos" o "poemas de la forma" (caligramas) (figura 10), que si bien no pueden ser considerados el fruto de una decisión de diseño,

ejemplifican con claridad lo que puede conseguirse al romper el paradigma de las alineaciones tradicionales, al apelar a un recurso visual no solo como apoyo, sino como parte integral de la esencia del poema.

THE LOST AND FOUND DEPARTMENT OF DREAMS; BRUSSELS (Z1 mmerman, 2003)

$$
\text { For Dande. }
$$

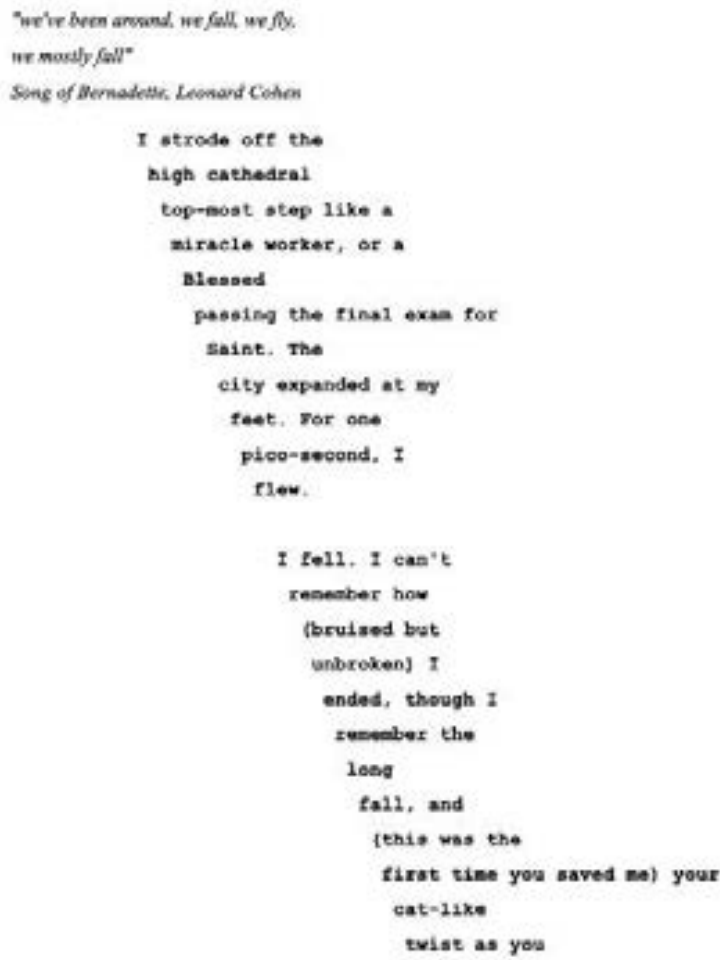

taster than the grab of gravity

below no. so

yeur ebeat protected

or fase,

youx arma

wrapped around me,

your body

grated tor mine agaisat

grenite, mile wo

tumbled like

east=out

angels. 
Otro conocido ejemplo de este tipo de trabajo, es el del poeta ecuato. riano Jorge Eduardo Eielson (1924 -2006) llamado Poesía en forma de pájaro (figura 11)

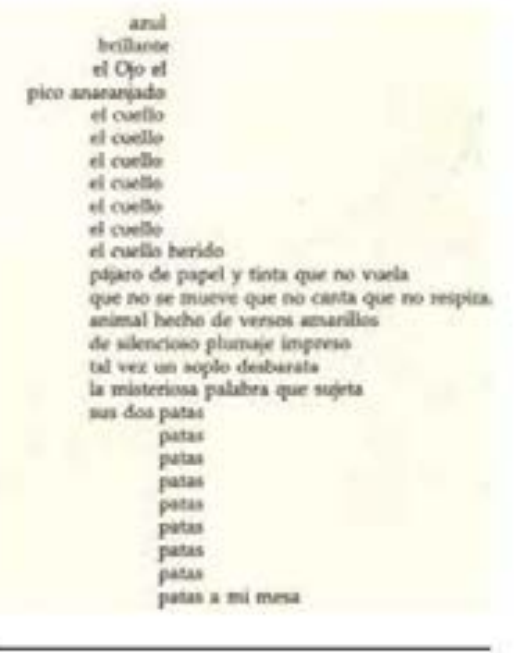

Figura 11. Poesía en forma de pujjaco Fuente: hetp://lacomuridad.elpass.com/ atrapadordesuenos/category/poesia/ 10

9. Linea de base de texto (Base line).
Las letras se mueven entre los espacios marcados por las líneas de alineación superior, de alineación media superior y de alineación inferior. La línea que soporta la letra mayúscula y basa a las minúsculas, es la línea de base de texto. Aunque no es mury usual su modificación, es importante enfatizar que en cualquiera de las opciones que se considere hacerlo, se ha de mantener un sentido positivo para la lectura del texto. La inclinación de la estructura es otra posibilidad y la opción más recomendable es generar giros exactos destinados a facilitar el manejo de los elementos en la estructura y las oposiciones determinadas en el diseño. Sea cual sea la angulación propuesta, es importante no perder de vista el eje y proponer las variaciones con rigor geométrico (Figura 13).

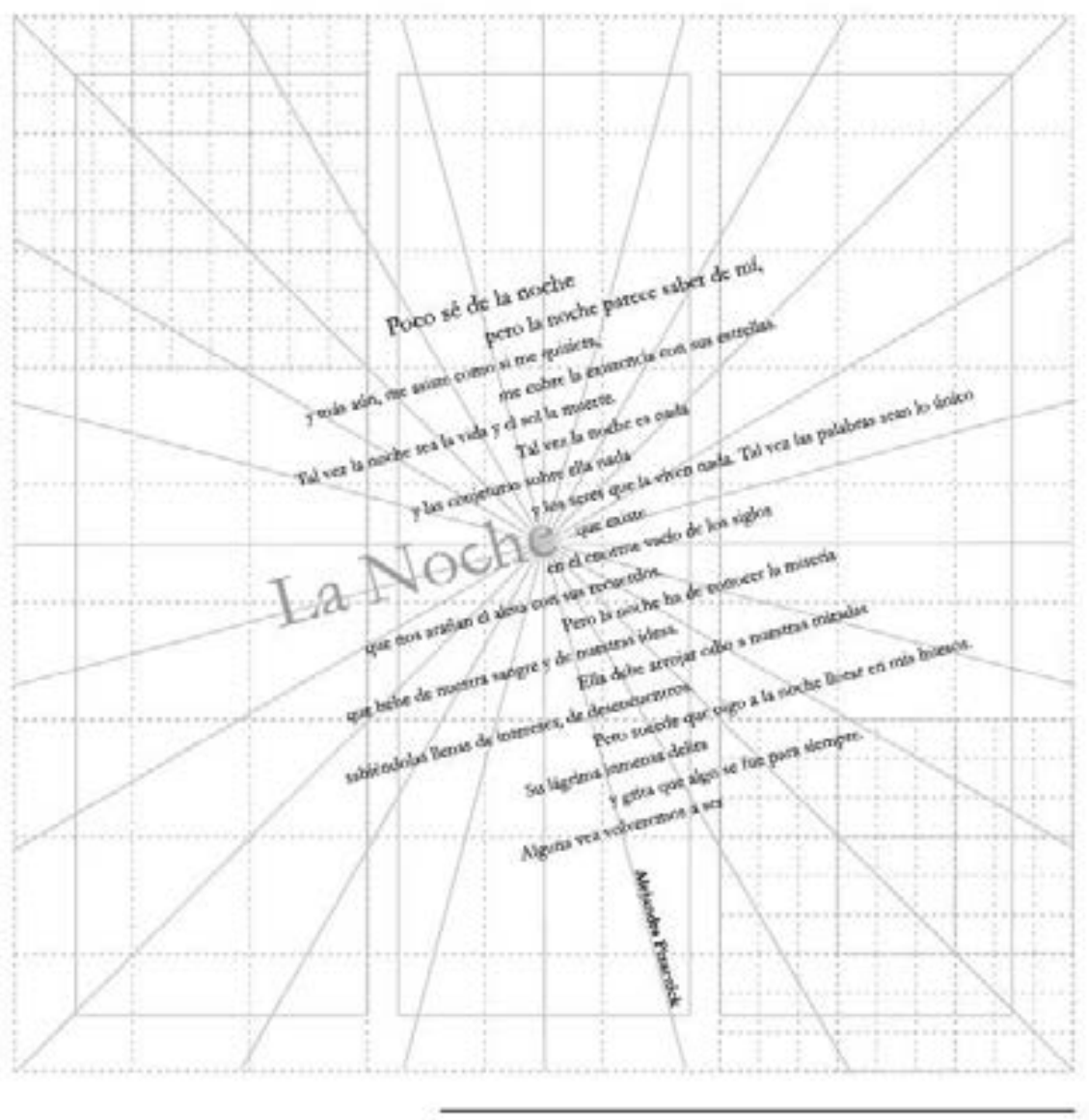

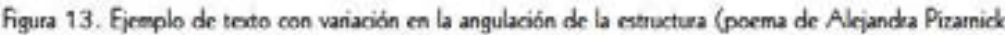
compuesto en Garamond, diferemtes puntajes, peopuesta de alinesción e interlinea amplia).

Figura 12. Lineas de movimiento de la letra fuente: Autcra 
Dado este tipo de trabajo con la

mancha tipográfica, el tiempo se

asemeja a un compás, a la música, a la

danza, tal vez al murmullo del viento

colado en las estructuras arquitectónicas

durante las tardes silenciosas. Este

tiempo es una clara determinación del

diseñador, un juego con la imaginación

del lector. Se asigna una métrica nueva

a cada línea de texto que no es dibujada,

solamente insinuada por el peso

propio de los caracteres (figura 14).

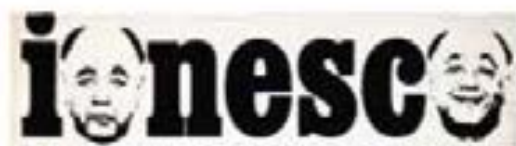

LA CANTATRICE CHAUVE

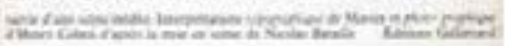
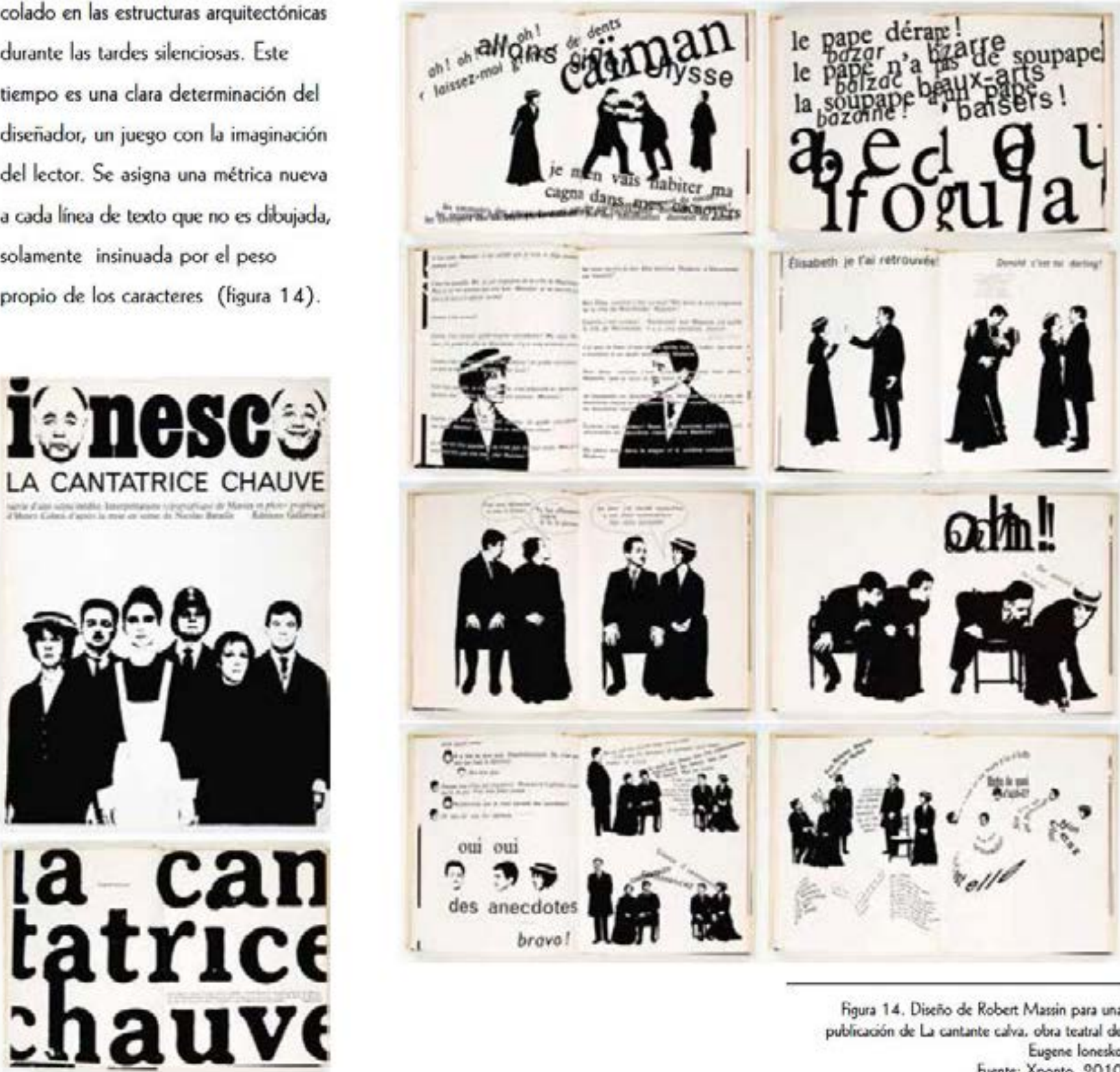

Figura 14. Diseño de Robert Massin para una publicacóón de La cantante calva. obra teatral de Eugene lonesko Fuente: Xponto, 2010 


\section{Las variables del texto}

Contar con las posibilidades de una fuente en sus diferentes variaciones, generadas por una inclinación del eje central de la letra, su condensación o su compresión, hacen más fácil la selección tipográfica. Tradicionalmente se recomienda -y desde el uso corriente es común-emplear dos o tres fuentes distintas en una sola pieza. Apropiarse de las variaciones del texto ${ }^{3}$ en las acepciones presentadas permite un diseño jgil, moderno, sin ruidos ${ }^{4}$ excesivos que distraigan al lector del objetivo inicial. Asi, el diseñador accede a opciones razonables y estéticamente ricas, al tiempo que se incentiva la lectura eficiente (figuras 15 y 16 ).

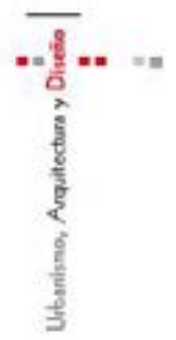

103

Thas variaciones de texto hacen referencia a La distintas presentaciones de una fuente tipografica, las cuales surgen al modificar su condensación y compresión, o al generar una inclinación en el eje vertical. Básicamente, estas variaciones pueden ser: negrita, black, extra black, light o thin; otendida o comprimida e itślics. Amprecisiones en el diseño, elementos superfluos, decoración innecesaria, uso de esquemas cromáticos arbitrarios.

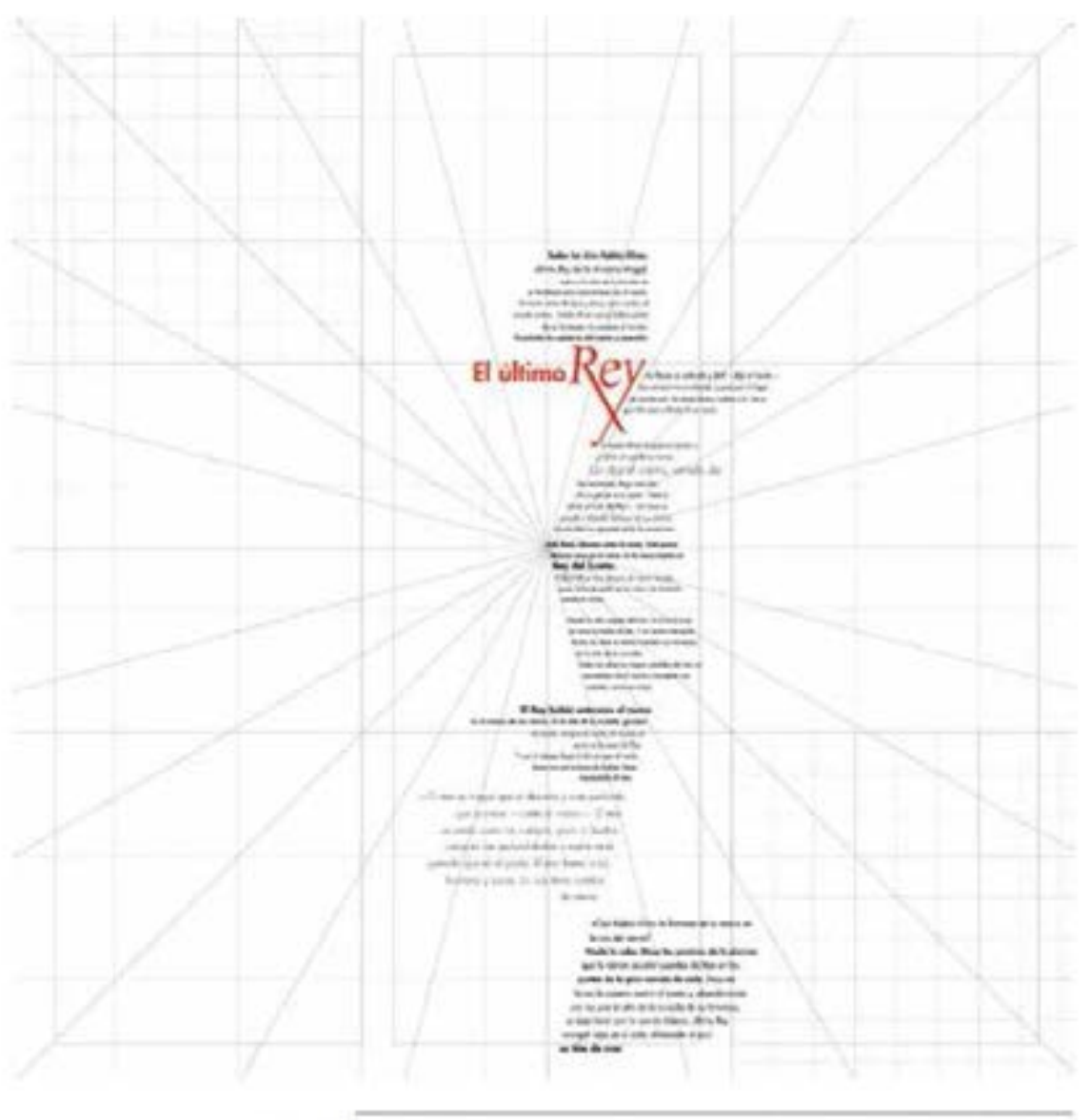

Figura 15. Ejemplo de cuento compuesto en caxateres de tipo futura, diseriado medinte la aplicación de toctos con variación en su condenasoón y puntaje. Fuente: Autcea 
Mie pedia a gritos

$-n \operatorname{cosid}=$

4 todos sus cauriches acceptar:

ceanción tresiensuascant

eib a 8 es

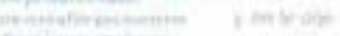

$\ldots \ldots, x^{8}$

Iacuarta y út ima

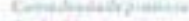

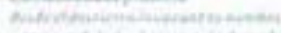

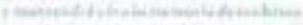

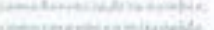

nosedistingutr

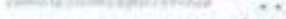

Comanow

nesere

$=$

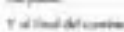

pondats

20itom

comitom

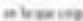

itantads

+

rats.

4.m.

-

winte

Titumans.

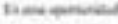

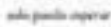

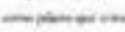

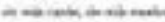

pertmont

Yamis

dasmmine

mimeitumitiven:

motrits

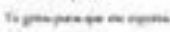

taspras

canción das

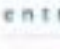

entrebesos y raice

nesedintogum thing

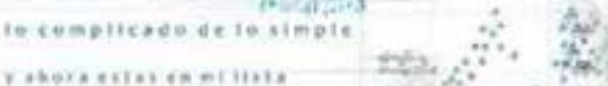

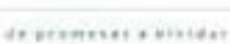

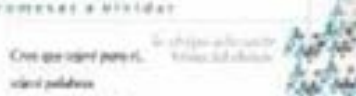

comentombly

atumber

+tom-

mantions 3

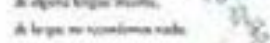

initin

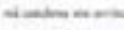

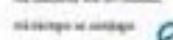

and

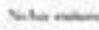

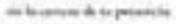

vormmone

simact

venomatr.

mancisto

anme

onmenes

intrit

vinmonem

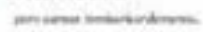

inabioner of

-

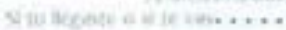

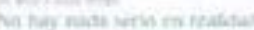

Solo umas horas nade mas

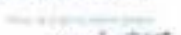

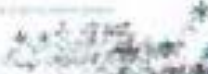

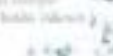

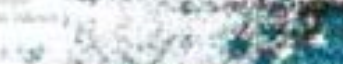

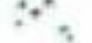

5

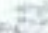

conción uno

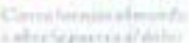

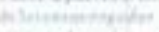

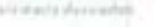

So you yinh that is subr:

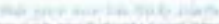

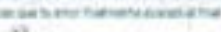

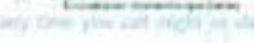

and

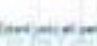

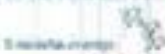
the min.
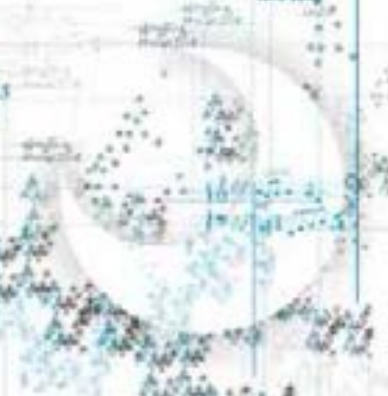

sitis

ber cada nota que acompare

inconfeso de los mortales

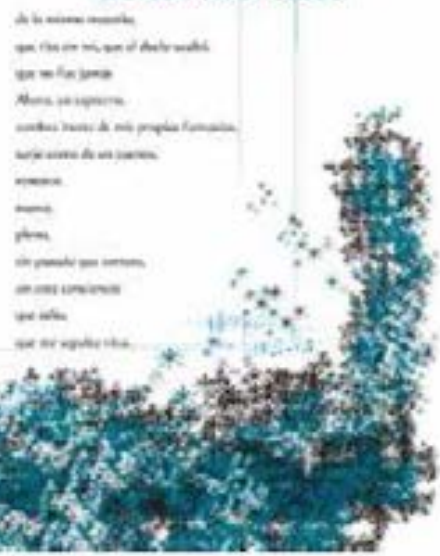

Figura 16. Elomplo de púgina diseriada pasa revista, compuesta en caractetes de dos tipos distintos, varixción de puntaie, alinearón e interlines. Fuente: Avtcra 


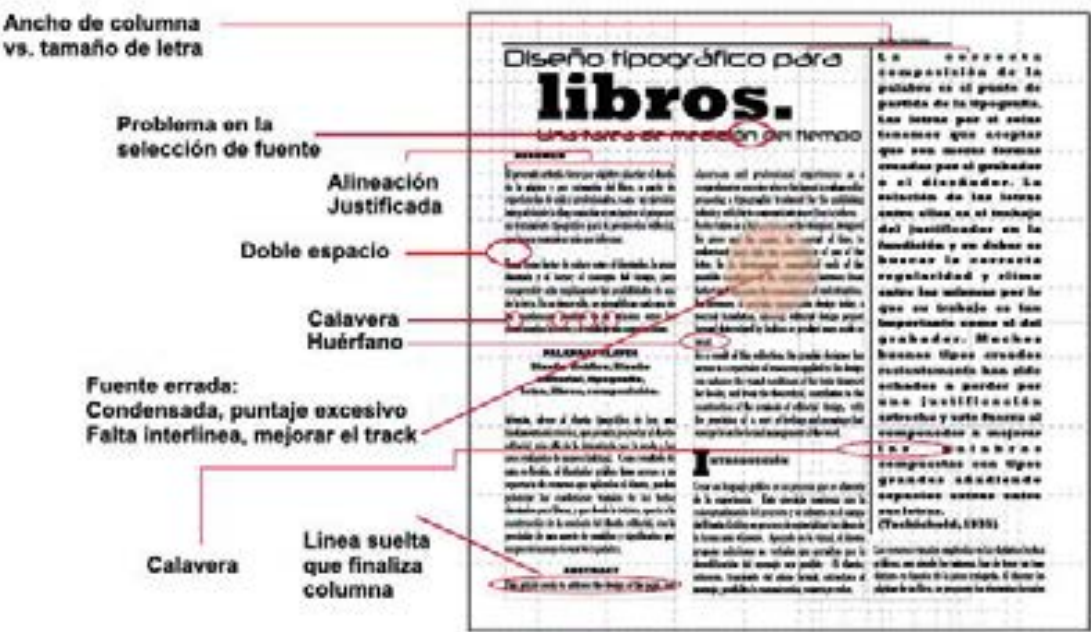

Figura 17. Ejemplo de texto con enores en el disetho tipogratico que dificultan la lectura

Fuente: Autora

1. Uso de tipos de card́cter ornamental, gótico o manuscrito en textos de cuetpo largo. Esta parece ser una recomendación innecesaria, pero en la medida que el trabajo del diseñador gráfico está siempre sometido a apreciaciones no profesionales, es importante poseer los argumentos para refutar la inclusión de estos tipos. Tales familias ofrecen una mancha tipograffica demasiado densa, con graves dificultades de lecturabilidad que los hacen poco prácticos para su eficiente composición. Incluso en titulaciones o rotulaciones sencillas su uso debe estar absolutamente controlado y determinado por necesidades muy especificas.

A partir de estas consideraciones, quien se interese en el diseño de tipografía aplicado a ediciones, debe reconocer tanto los elementos que no resultan funcionales para su trabajo (figura 17) como aquellos que lo fortalecen (figura 18). A continuación se presentan recomendaciones esenciales en este sentido.

Pueden ser aplicables conceptualmente, pero de igual forma se deben valorar sus condiciones de estructura, el equilibrio en los vanos, el contraste de las astas y especialmente el kern, ya que muchos de estos caracteres han surgido de mutaciones o intervenciones personales de diseñadores a otros tipos, pero no se han estudiado a conciencia sus posibilidades de uso ni sus variables. Dada la facilidad para hacerlos circular de forma gratuita por internet, su aplicación normalmente tiene fallos.

2. Implementación de tipos en caja alta, exclusivamente.

La recomendación es puntual: los tipos implementados de esta manera (basados en la composición geométrica angulosa de las mayúsculas) dan como resultado líneas 


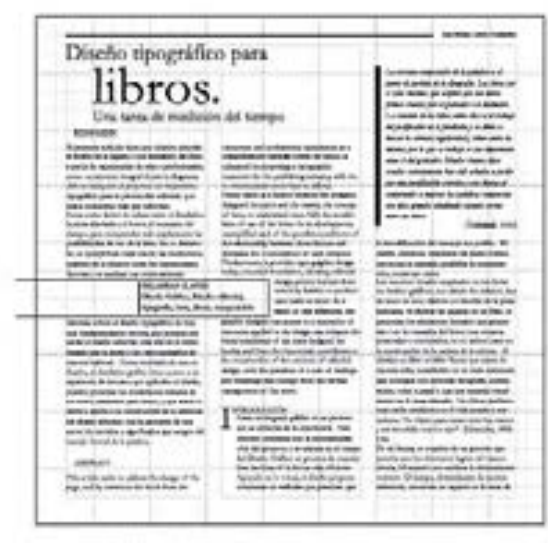

Figura 18. Ejemplo de tecto cuyos elementos de diseño tipog thico contribuyen a la calidad de la lectura. Fuente: Autora

sJan Tschichold, disetiudor que en 1928 editó de forma ampliada sus preceptos enunciados en 1923 bajo el título de "La Nueva Tipografia", nombre que finalmente. adoptaria ef movimiento tipográlico alemán de los años 20 , en el que tuvieton uns notoria influencia las obars graficas de El Lissitzky y Lazlo Moholy-Nagy. (cf. Satué, 1990, p. 180). quebradas, de dificil lectura, hostiles. Por lo general, el trazo de las mayúsculas está desarrollado a partir de líneas rectas, ya sean ellas verticales, diagonales u horizontales. Carecen de trazos curvos, que son los encargados de enlazar y conferir fluidez visual, caracteristica que hace un texto amable. Aun siendo bellas, las mayúsculas se perciben demasiado rígidas, duras y agudas. Estas particularidades pueden ser evaluadas de manera positiva en virtud de la extensión del texto, pero en términos generales, las minúsculas son más fáciles de leer, contienen trazos más agradables por ser más redondas, y usadas en conjunto con las mayúsculas, posibilitan la aparición de textos con un mayor valor expresivo.

3. Falta de estructura del cuerpo tipográfico.

De acuerdo con la definición dada por Wucius Wong (1980), en diseño "la estructura por regla general, impone orden y predetermina las relaciones internas de las formas de un diseño. Podemos haber creado un diseño sin haber pensado conscientemente en la estructura, pero la estructura está siempre presente cuando hay una organización" (p. 27).

La condición contraria, es decir cuando no existe estructura, puede decirse que es, en resumen, la menos tangible de todas: equivale a una valoración sencilla de las condiciones de una fuente a primera vista. El desequilibrio, las fallas en el interletraje, la exageración innecesaria de ciertos detalles, la composición arbitraria del carácter o simplemente la ausencia de armonía en los trazos, son factores que determinan la falta de estructura. Caet en este tipo de errores corresponde a una evaluación incorrecta del tipo.

Una propuesta tipográfica dictada por la moda o por una pobre interpretación del concepto, solo redunda en un trabajo no profesional. Después de una mala selección de tipografía, lo mús lógico es esperar todo tipo de incorrecciones en la aplicación de la mancha tipográfica. Al respecto, Satué cita a Jan Tschicholds quien al referirse al correcto uso de la tipografía por parte del diseñador, señala: 
Todas las consideraciones planteadas solo son parte de lo que un ojo bien entrenado debe tener presente. De ellas se desprende un primer ejercicio de profesionalización del trabajo del diseñador, pues si bien son detalles que construyen, a los que se sensibiliza quien está especialmente atento a ellos, por lo general se desprecian. Esto es así ya que, de ninguna forma,

dichas fallas puedan negar la posibilidad de leer un texto, pues el simple hecho de reconocer un idioma y tener las condiciones humanamente necesarias para hacerlo, resulta suficiente.

Todo lo requerido para generar un diseño en que los elementos estén bajo control se encuentra más allá, se percibe, se aprende a medir, está implicito en el intangible perfecto total esperado de esta actividad. Es sin duda una tarea dispendiosa, que requiere no solo de entrenamiento y tiempo, sino de una condición particular, lograda con mucho trabajo y práctica. De estos detalles, tratados con profesionalismo, se obtiene ese manejo calculado de los tiempos que afectarán directamente a quien lee. Desde lo visual se consiguen las horas requeridas para que el lector logre el objetivo propuesto al comenzar con el ejercicio. Se involucra en el objeto de su lectura con placidez y aprende a reconocer los rincones de lo leido. Se enriquece el proceso y

La tipografia deberia subordinarse enteramente a la función de transmitir la información clara y diferencialmente seguir las normas introducidas en la época y crear, en relación con su misión social, un orden estético a nivel de contenido. Todo formalismo intuitivo debería ser evitado y la forma debería derivar lógicamente del contenido (Satué, 1990, p. 180). la inicialmente buena obra se torna magnífica por lo que es y por ser parte de una experiencia personal.

El resultado del manejo de los tiempos (el de producción o el del recorrido de la lectura) que afectan al lector, se asemeja al efecto del tiempo en algunos fermentados: los madura, les destaca ciertos brillos, los hace lo que son. Sin ello, serían un simple jugo de cosas, probablemente con buen sabor. Tiempo prudente al diseñar para tener la oportunidad de enfrentar al producto con delicadeza. Un tiempo que se corresponda con el empleado por quien lee en la construcción de su universo.

A final, un tiempo inmensamente productivo en el recuento del lector al lograr aprehender aquello entregado por las páginas. En suma, la perfección que enamora y realmente fascina. 
El tiempo futuro, para el universo del diseño editorial, presagia variaciones que bien podrian asemejarse en sus cruciales repercusiones históricas con el nacimiento de la imprenta de Gutenberg: "no surgen de la desesperación cultural, ni de una rebelión estética, sino de las nuevas tecnologías" (Epstein, 2002, p. 18). Pero de ninguna manera representan la callada muerte del libro impreso bajo el innegable peso de internet. Por el contrario, prometen amplios espacios de trabajo al diseñador.

De acuerdo con lo citado por el creador de la editorial Anchor Books, Jason Epstein ${ }^{6}$, la industria editorial se encuentra ante un futuro en que las infinitas posibilidades ofrecidas por las nuevas tecnologias "no suprimen el pasado, sino que edifican sobre él". Si bien algunas dinámicas como hoy las conocemos (tal es el caso de los envios o el almacenamiento) se tornarán obsoletas, otros recursos como el soporte editorial, la publicidad y el diseño, retomarán el valor de tiempos pasados para dar un giro de 180 grados y generar una transformación semejante a la inicial configuración: "industria artesanal compuesta de diversas y creativas unidades autónomas" (Epstein, 2002, p. 176).

\section{CONCLUSIONES}

Diseñar las páginas de un libro hace parte de la escritura del mismo, de un modo diferente que es consecuente con el diseñador y su propio universo. A diseñadores de universo limitado, diseños limitados.

Nason Epstein, director editorial durante 40 ainos del sello editosial Random

House, editó a numerosos novelistas de gran importancia y ha sido galardonado internacionalmente por inventar nuevas maneas de publicar y editar.
El estudio detallado de los diferentes recursos gráficos hace posible la transmisión de mensajes y saberes. En nuestros tiempos, poseer conocimiento o tener acceso a la tecnologia que facilite el proceso es imprescindible, pero sólo quien se sensibiliza ante el infinito espectro de posibilidades del manejo tipográfico, está en condición de construir las redes necesarias que permitan al lector atrapar ese mensaje o saber. Diseñar páginas para libros es una tarea de medición del tiempo. El diseñador posee la inconmensurable capacidad de transportar en las épocas a su lector, jugar con su percepción hasta hacerle perder las nociones que tiene de dicho tiempo. 
A partir de las diferentes relaciones expuestas podemos verificar que la palabra escrita, y por extensión el libro, son soportes de universos intangibles creados por la mano del diseñador, en un ejercicio del todo consiente del valor de lo dicho visualmente. De la destreza de este profesional, de su capacidad y control, dependen la eficacia de la lectura y la huella que ésta deje en el lector común.

El diseño tipográfico para propuestas editoriales suele tratarse como un recurso supeditado al contenido o inferior a la imagen explícita. A partir de las reflexiones presentadas, se reconoce el amplio valor que, en la construcción del libro y en su posterior interacción con el lector, posee el trabajo profesional.

Una solución técnicamente correcta al tratamiento tipográfico es suficiente para controlar los tiempos en la lectura. A su vez, funciona como un apoyo para quien trabaja en el diseño y la producción de libros y otros medios impresos, indistintamente del recurso tecnológico con el que se cuente.

Antei, G. (1992). Marta Granados, Cuestiones de estilo. En M. Granados (Ed.). Un Mundo Gráfico (pp. 24-29). Bogotá: OP Grálicas.

Baines, P. H. (2005). Tipografía. Función, Forma y Diseño. Barcelona: G. Gili.

Contreras, S. (2012). La tipografia como cantante. Recuperado el 18 de marzo de 2012, de http://Foroalfa.org/articulos/la-tipografia-como-cantante

Epstein, J. (2002). La industria del libro. Pasado, Presente y futuro de la edición. Barcelona: Anagrama.

Gaitto, J. (2008). Cátedra Gailto. Apunte Nº Interletrado Estudio de los Blancos. Buenos Aires: Universidad de Buenos Aires FADU 
Gaitto, J. (2008). Catedra Gaitto. Apunte $N^{\circ} 4$ Variables Espaciales. Buenos Aires: Universidad de Buenos Aires FADU

Granados, M. (1992). Un mundo gráfico. Bogotá: OP Gráficas.

López, C. M. (2008). La astronomia en América: Mayas, Aztecas e Incas. Recuperado el 19 de diciembre de 2011, de http://www.manizales.unal.edu.co/ oam manizales/93.pdf

Puertas, C. (2012). Sin reglas ni compás Recuperado el 2 de Febrero de 2012, de http://foroalfa.org/articulos/sin-regla-ni-compas

Satué, E. (1990). El Diseño Gráfico, desde sus orígenes hasta nuestros tiempos. Barcelona: Alianza.

Tschichold, J. (1935). Typographische Gestaltung. Recuperado el 4 de marzo de 2011, de http://www.unostiposduros.com/?p=1165

Wong, W. (1980). Fundamentos de diseño bi- y tri- dimensional. Barcelona: G. Gilli.

Xponto. (2010). Robert Massin. Recuperado el 2 de febrero de 2012, de http:// xponto. wordpress.com/

Zimmerman, J. (2003). The lost and found department of dreams: Brussels. Recuperado el 9 de noviembre de 2011, de https://docs.google.com/a/unibo-

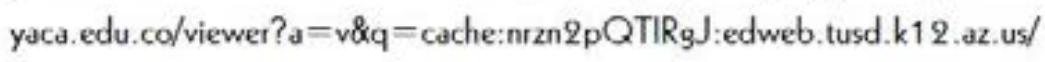
kgarbe/writing/poetry/Samples_How\%2520to/concrete\%2520poems.doc + THE + LOST + AND + FOUND + DEPARTMENT + OF + DREAMS: + BRUSSELS\&hl = es\&gl = co\&pid = bl\&sicid = ADGEESIQ1 EoabAlr6RaS 